\title{
Design of Packaging Pattern
}

\author{
Li Suo ${ }^{1}$, Yingwei $\mathbf{L i}^{1}$ \\ ${ }^{1}$ Jingdezhen Ceramic Institute, Jingdezhen, Jiangxi, 333403
}

Keywords: packaging; pattern design; people sense

\begin{abstract}
In life, each commodity strongly stimulates people's senses in different ways, arousing the desire to buy. It can be said that the charm of packaging is an irresistible yet attractive selling method in modern society. Each well-designed package is enough to stimulate inner impulse. So from a certain point of view, what people actually buy may not be the product itself, but a concept of packaging or a culture and character that goes beyond it. Successful packaging design can impress people and directly affect consumers' desire to purchase. The integrated application of "five senses" in packaging design brings new sensory experiences to consumers, stimulating consumers' sensory organs through different colors, materials, tastes, and sounds, thereby affecting consumers' psychology, and thus achieving consumer purchases.
\end{abstract}

\section{Introduction}

The positioning of brand packaging design is to clearly express to consumers what "I am" and "What is my production?". The logo of commodity packaging and companies is registered with the Trade and Industry Bureau. They are protected by national laws. Once a commodity is a well-known brand, it will bring huge intangible assets and image charm to the company, bringing quality to consumers. Guarantee and consumer confidence. The feature of commodity brand positioning is to highlight the brand's visual image in packaging design and deepen consumer awareness of brand image. Brand packaging design should start from the elements such as graphics and colors. After considering the characteristics of the products, we should follow some basic principles of brand design so that all design elements can be coordinated and matched to each other. From the perspective of marketing, the graphics and color design of brand packaging design are important factors that highlight the characteristics of the product and are the most effective promotion methods for brand image [1].

\section{Highlight the Graphic Design of Brand Packaging}

Branded packaging image: including promotional images, logos, cartoons, auxiliary graphics, etc. In packaging design, only the full use of the expressiveness of the main graphics can enable consumers to create rich associations of graphics and products in reality. Helps promote the vivid expression of product images. For example, the denim image of Marlboro cigarettes and the red geometric aid graphics on the packaging, the Kirin image on the Kirin beer packaging in Japan, and various cartoon images appearing on the packaging.

Logo image of brand packaging: In general, the packaging graphics should fully display the brand's logo characteristics, so that consumers can immediately identify the company's products from the graphics, especially brand-name products and brand stores, eye-catching graphics can play a role in attracting consumers. Important role. Changes in packaging materials can also attract people's attention, such as porcelain gifts exported from Henan, ingeniously packaged into portable boxes made of corn bran, so that cheap materials can be transformed into folk crafts packaging to form an unforgettable memory. The visual impression. Highlighting the font image of brand packaging: Because of its readability and non-repetition, the font image of the brand has become one of the main manifestations of brand personality. Like Coca-Cola's brand font, McDonald's " $M$ " letter image, constitutes the most important part of image expression in the packaging. The configuration of the fonts and backgrounds in the graphic must attract the attention of customers in 
order to establish a brand image and effective purchase behavior.

\section{Color Design of Brand Packaging}

Color plays a particularly important role in packaging design. In the fiercely competitive commodity market, it is necessary to design and use color in order to enhance the people's memory of the brand by clearly distinguishing the visual features of other products from other products. Highlight the color of brand packaging design: When designing brand packaging, several fixed color combinations are usually formulated as the "image color" of the company's products, giving consumers a strong visual impression. For example, the green color of Fujifilm, the medium yellow of Kodak film, and the big red color of Coca-Cola all have a strong visual appeal. Emphasize the color of the product image [2]. It is not just transparent packaging or the use of color photographs to express the inherent color of the product itself. Instead, it uses more of the product's image color, which enables consumers to generate similar signals and rapidly determine the content of the package. Different commodity packaging has different color requirements: In order to more accurately grasp the different color requirements of commodity packaging, we classify the consumer goods into three categories, and put forward the specific requirements for color design respectively: Luxury goods: Cosmetics, alcohol, chocolates, etc. This product's color design should have a special atmosphere and a sense of luxury. Such as French cosmetics, there must be a mysterious atmosphere, a romantic atmosphere. Like whiskey, there must be a special temperament in the life of French nobles in the 18th century. In short, the packaging of such products should give people a feeling of high-priced brand names [3]. Daily life foods: such as cookies, condiments, coffee, black tea, etc. The color design of this kind of product packaging should have two characteristics: It will cause the appetite of consumers and deliberately highlight the product image. For example, mineral water packaging adopts blue color, which implies coolness and purity, and fully transparent plastic bottles, fully displaying the product's feature. Popular products: such as middle and low-grade cosmetics, soap, protective equipment and so on. Such products are located in the mass market, and their packaging color design requirements: To display an atmosphere that is easy to get close to; To express the sense of quality of goods; To make consumers identify the brand in a short time. The use of colorless systems in packaging design: black, white, gray, gold and silver are called neutral colors. With respect to colored systems, there are no obvious hue deviations, so they are called colorless systems and they are all in harmony with any color combination in a colored system. In the colorless system, black and white are two extreme colors. Black gives a solemn, solemn, inward-looking positive effect. White gives people a sense of launch, clarity, and breathability. It has a dual symbol of quietness, purity, and lightness. Gray has inherent meanings such as ordinary, gentle, ethereal and moderation, which can increase the level of the picture and make the picture richer and more decorative. The gold and silver, because of their unique gloss and price, have become a symbol of nobility, elegance, and luxury. They are commonly used as decorative colors and decorative colors. The colorless system of gold, silver, black, white, and gray is called the eternal fashion color. In many packaging designs with a colorless system as the main component, some high-purity colors are often adorned during the period, which contrasts sharply with the colorless system. The special nature of the colorless system provides a stage for the full display of charm for the packaging design of many commodities, improving the quality and grade of the commodities, and enhancing the sense of the times and personality of the commodities.

\section{Advantages of Combining Traditional Chinese Patterns with Modern Gift Packaging Design}

From the perspective of consumers' psychological needs, Chinese traditional patterns are used in modern gift packaging to enable consumers to receive spiritual satisfaction, feel ancient and rich ethnic characteristics, and satisfy consumers' pursuit of traditional culture and art. This enables the presenter and the person to be presented to meet social needs and self-respect needs at the same time, showing the sincerity and elegant taste of the presenter and respect for the person to whom the 
presenter is presented, thereby strengthening the social connection between the two. From the point of view of social development, the design style based on Chinese traditional patterns combined with modern gift packaging design enables the gift packaging design to have rich cultural connotations and characteristics of the times. People living in an environment with a cultural atmosphere are one aspect of the change in the living environment and a manifestation of the improvement of the quality of life [4].

From the point of view of the package designer, the essence of Chinese traditional patterns, combined with modern techniques, improved modern gift packaging design, will inject fresh blood into modern gift packaging design, open up new design styles, and find modern packaging designs. New breakthrough. From the point of view of modern production methods of gift packaging, the design ideas of modern gift packaging can be divided into three types: 1) Produced by manufacturers to meet the needs of consumers for gift giving, with the purpose of sales, which is also traditional gift packaging. Design ideas; 2) Corporate-specific promotional gift packaging for corporate image-raising purposes to increase corporate awareness or status. Not for profit purposes. Design focuses on displaying corporate culture and image. This is based on corporate identity design. A new design idea for gift packaging brought about by popularization; 3) With the emphasis placed on the promotion of urban image in recent years, it is purchased by the government as part of a custom, as a gift for exchange between government departments. This type of gift packaging design reflects the dignity of the government departments, but also reflects the characteristics of the city's customs and culture. The design requirements are relatively high, and it is necessary to draw nutrition from Chinese traditional patterns. This opens up a new design idea for modern gift packaging design, Expanded the scope of gift packaging design. Chinese traditional pattern design style is applied to modern gift packaging, which is conducive to satisfying consumers' increasing aesthetic demands, improving the quality of life, facilitating the development of modern design, and bringing new designs to the development of gift packaging design Ideas [5].

Chinese traditional patterns applied to modern gift packaging must be combined with modern techniques to improve. Drawing on the design styles of Chinese traditional patterns, the first must be improved from graphics, color, modeling, etc. to suit modern gift packaging design. According to the requirements of the traditional pattern combined with gift packaging design, it is simple and lively and true and deep. "Plainness and vividness" is the use of exaggeration, generalization, and refinement to carry out the strengthening of the United States. Through the transformation to obtain a vivid, full of characteristics of the typical image graphics, the so-called "deformed and odd" "deformed and clever" is the best decorative summary, "change" in modern thinking, dissolved in fashion, to meet the modern Human aesthetic needs. "True and deep feelings" means that the characteristics of traditional patterns are not satisfied with the natural reproduction. The use of traditional patterns on gift wraps is not satisfied with copying but should be devoted to the designer's feelings to make them more artistic, idealized, and more relevant. In the characteristics of gift packaging, only decorative patterns designed specifically for packaging have their vitality.

\section{Conclusion}

With the diversification of consumer demand and the segmentation of commodity markets, the requirements for packaging graphic design and color design have become more and more strict and meticulous. In today's highly competitive shopping malls, it is necessary to make products have obvious visual characteristics and have stronger appeal, which can stimulate consumption, guide consumption, enhance people's memory of brands, and the individual requirements of graphic design and color design of packaging and packaging. It is even more important.

\section{References}

[1] Wang Hui, Xiao Qiina. The application of folk paper-cut art in packaging design [J]. Decoration, 2006 (2): 37. 
[2] Lou Zhengguo. The use of traditional folk art in packaging design [J]. Packaging Engineering 2006, 27 (5): 152.

[3] Hu Fei. Exploration of Traditional Chinese Design Thinking Mode[M]. Beijing: China Architecture Light Industry Press, 2007.

[4] Chen Xu. Packaging Design of Non-material Society [J]. Packaging Engineering, 2004, 25(4):199-200.

[5] Li Xiaohong. Research on the Added Value of Commodity Packaging Design [J]. Packaging Engineering, 2007, 28(4):157-159. 